\title{
Article \\ Comparative Study of Bacterial Isolates in Ovine Mandibular Osteomyelitis and Oral Microbiota of Healthy Sheep
}

\author{
Marta Ruiz de Arcaute ${ }^{1}$, Delia Lacasta ${ }^{1, * \mathbb{D}}$, Juan Pedro Bueso ${ }^{2}$, Luis Miguel Ferrer ${ }^{1}$, José María González ${ }^{1}{ }^{(\mathbb{C}}$, \\ Sergio Villanueva-Saz ${ }^{1}$ and Juan José Ramos ${ }^{1}$ \\ 1 Animal Pathology Department, Instituto Agroalimentario de Aragón-IA2, Veterinary Faculty of Zaragoza, \\ Universidad de Zaragoza-CITA, C/Miguel Servet 177, 50013 Zaragoza, Spain; martarda@unizar.es (M.R.d.A.); \\ lmferrer@unizar.es (L.M.F.); jmgsovino@gmail.com (J.M.G.); svsbarrachina@gmail.com (S.V.-S.); \\ jjramos@unizar.es (J.J.R.) \\ 2 Laboratorio Agroambiental de Aragón, Montañana, 50059 Zaragoza, Spain; jpbueso@aragon.es \\ * Correspondence: dlacasta@unizar.es; Tel.: +34-6-096-76727
}

check for updates

Citation: Ruiz de Arcaute, M.; Lacasta, D.; Bueso, J.P.; Ferrer, L.M.; González, J.M.; Villanueva-Saz, S.; Ramos, J.J. Comparative Study of Bacterial Isolates in Ovine Mandibular Osteomyelitis and Ora Microbiota of Healthy Sheep. Appl. Sci. 2021, 11, 3925. https://doi.org/ 10.3390/app11093925

Academic Editor: Elena Sofia Inguglia

Received: 31 March 2021

Accepted: 23 April 2021

Published: 26 April 2021

Publisher's Note: MDPI stays neutral with regard to jurisdictional claims in published maps and institutional affiliations.

Copyright: (c) 2021 by the authors. Licensee MDPI, Basel, Switzerland. This article is an open access article distributed under the terms and conditions of the Creative Commons Attribution (CC BY) license (https:/ / creativecommons.org/licenses/by/ $4.0 /)$.

\begin{abstract}
Microorganisms involved in ovine mandibular osteomyelitis (OMO) have not yet been deeply studied. The aim of the present study is to elucidate the microorganisms involved in OMO, comparing them with the microorganisms found in the healthy oral cavity of sheep. Two hundred and five samples were taken from mandibular osteomyelitis lesions, and they were compared with the microbiological results of samples obtained from twelve periodontally healthy sheep. Sixty-four samples (32.98\%) of OMO lesions showed pure growths, while $130(67.01 \%)$ were mixed cultures. Microorganisms of the genus Streptococcus were the most frequently isolated $(20.95 \%)$, followed by bacteria of the genus Pseudomonas (8.50\%), Trueperella pyogenes $(7.26 \%)$, Staphylococcus $(6.63 \%)$ and Escherichia coli (6.22\%). Ninety-one different isolates were obtained from healthy mouths, and again, microorganisms of the genus Streptococcus were the most frequent $(16.48 \%)$, followed by bacteria of the genus Staphylococcus (13.18\%), Pseudomonas (9.89\%) and Moraxella (6.59\%). Based on these and previous results, it could be concluded that the normal microbiota of the oral cavity could be involved in the development of OMO lesions when there is an injury of the gingiva that enables the entry of bacteria to the oral mucosa that eventually settle locally in bony tissues, causing mandibular osteomyelitis.
\end{abstract}

Keywords: sheep; oral microbiota; ovine mandibular osteomyelitis; bacterial isolates

\section{Introduction}

Oral injuries are widespread disorders of sheep that can cause significant economic losses in farms. These usually painful conditions have relevant welfare implications because they prevent animals from feeding correctly, leading to chronic weight loss and, very often, cause final animals culling [1,2]. Periodontal disease is one of the most frequent oral disorders, and it can begin at an early age with gingivitis, which usually becomes chronic and leads to the accumulation of food debris around the tooth, below the level of the gum, that favours the progress of the infection in-depth, eventually causing mandibular inflammation [1-3]. In the literature, this disorder has been named "lumpy jaw"; swollen jaw; mandibular osteomyelitis or disease of the jaw. The term actinomycosis has also been used in sheep by extension of cattle, where this process has traditionally been related to the presence of Actinomyces bovis [4]; however, in sheep, the presence of this microorganism has not been reported in this type of lesions.

Ovine mandibular osteomyelitis (OMO) is a multifactorial disorder involving a range of host-pathogen-environment interactions, where host immunological and physiological mechanisms (host) interact with multiple etiological agents, including bacteria (pathogen), plus environmental factors (environment), such as the food accumulated in the teeth of animals affected of OMO $[2,5,6]$. OMO has also been related to an oral trauma with 
a subsequent secondary bacterial infection that induces the lesion [6,7]. In these cases, plant material has been found between the teeth and the alveolar bone, which provides access for environmental bacteria into the bone [5]. However, sometimes OMO has been associated with the entry of a specific and invasive microorganism, such as Pseudomonas aeruginosa [8-10], which can cause a severe acute outbreak.

The aetiology of ovine mandibular osteomyelitis is still unknown, although several studies have been performed trying to identify the bacteria associated with periodontitis in sheep [11-13]. Thus, in the study performed by McCourtie et al., Bacteroides and Fusobacterium organisms accounted for nearly $70 \%$ of the isolates [11]. Riggio et al. [12] found that the most prevalent microorganisms associated with ovine periodontitis were Mannheimia ruminalis and Moraxella caprae, and Borsanelli et al. [13] conducted a molecular study of the presence of bacteria of genera Porphyromonas and Prevotella, and they found that some of the species statistically correlate with ovine periodontitis. Likewise, the oral microbiota of healthy sheep has not been characterised yet.

The aim of the present study is to elucidate the microorganisms involved in ovine mandibular osteomyelitis, comparing them with the microorganisms found in the healthy oral cavity of sheep.

\section{Materials and Methods}

All procedures were carried out under Project Licence PI 11/16 approved by the Ethics Committee for Animal Experiments from the University of Zaragoza. The care and use of animals were performed accordingly with the Spanish Policy for Animal Protection RD53/2013, which meets the European Union Directive 2010/63 on the protection of animals used for experimental and other scientific purposes.

This study is the continuation of two previously carried out and published on ovine mandibular osteomyelitis $[2,6]$, and that all three are part of the research study carried out for a doctoral thesis.

\subsection{Sample Collection of Animals with Mandibular Osteomyelitis}

For the present study, 205 samples were taken from lesions of mandibular osteomyelitis of culled sheep for microbiological analysis. The affected animals were selected at the Mercazaragoza Abattoir, located in Zaragoza, Spain, from 1465 sheep heads examined during seven days. All the culled sheep received at the abattoir each day were examined. The particular characteristics of the farms of origin and the reasons for culling were unknown. In this abattoir, slaughtered sheep come from Spain's north-east region, where the main breed is Rasa Aragonesa, a local meat bread, and the predominant production system is semi-intensive, housing the animals at the end of gestation and during lactation and grazing the rest of the year. At the abattoir, the oral cavity of 1465 ewes were initially examined by inspection and palpation. The jaws from those animals with mandibular disorders were separated in order to perform a more detailed examination. Affected mandibles were immediately taken to the Pathological Service of the Veterinary Faculty of Zaragoza, Spain, to carry out a more comprehensive study.

Once the jaws reached the post mortem room at the Pathological Service of the Veterinary Faculty, a macroscopic study was carefully performed. The mandibles were inspected visually and by palpation, with particular attention paid to mandibular cheek teeth and mandibular bone. The age of the animals was estimated from an inspection of the incisor teeth. Most animals were judged to be older than six years, but a study of prevalences by age could not be performed because the age of all affected animals was not known accurately.

Two hundred and five of the ewes with mandibular lesions were sampled for microbiological studies. The mandibular bone was cross-sectioned through the affected area, and one sterile swab in Stuart culture medium was aseptically collected from the inside of each lesion. Samples were refrigerated at $4{ }^{\circ} \mathrm{C}$ until they were delivered to the Agroambiental Laboratory of the Government of Aragon in Zaragoza for subsequent microbiological analysis. 


\subsection{Sample Collection of Healthy Ewes}

Twelve periodontally healthy ewes were randomly selected from the farm of the Veterinary Faculty of Zaragoza, Spain. The age of the animals ranged from 3 to 6 years. The animals received at the faculty come from Rasa Aragonesa breed sheep flocks reared in a semi-intensive farming system. In the faculty facilities, the animals stay an average of two months, during which time they remain in permanent stabling fed with compound feed and straw.

For microbiological sampling, the mouth was opened with a mouth opener, and after verifying that there were no oral lesions, the sample was collected from the gingival margins using a sterile swab in Stuart culture medium. Similarly, the samples were refrigerated at $4{ }^{\circ} \mathrm{C}$ until they were immediately delivered to the Agroambiental Laboratory of the Government of Aragon in Zaragoza for subsequent analysis.

\subsection{Microbiological Analysis}

The analyses were carried out in all cases within $24 \mathrm{~h}$ after collection. Each sample was cultured in two Columbia blood agar plates (bioMérieux, Marcy-l'Etoile, France) and in a plate with the same elemental composition, but also carrying nalidixic acid and colistin (ANC) (bioMérieux, Marcy-l'Etoile, France), both selective for Gram-positive bacteria. MacConkey Agar (Difco Laboratories, Detroit, MI, USA) and plates for anaerobic Gramnegative bacteria (AS added from Schaedler's broth with neomycin gentamicin) were also inoculated. One of the AS and ANC plates were incubated in a humid atmosphere enriched with $10 \% \mathrm{CO} 2$. All plates were incubated at $37^{\circ} \mathrm{C}$ for $72 \mathrm{~h}$ and observed daily to check for growth. Once growth was obtained, exhaustion passages were made to other agar plates to obtain pure cultures. The isolates were identified from these cultures following the methods described in Bergeys' manual [14]. Phenotypical characters included colony morphology, Gram staining, catalase and oxidase, nitrate reduction, urease, coagulase, $\beta$-galactosidase, indole production, acetoin production, use of citrate as a sole carbon source, acid production from glucose, sucrose, sorbitol, inositol and trehalose, H2S and gas production on TSI agar, ornithine and lysine decarboxylase and arginine dihydrolase. In addition, rapid identification methods, such as API galleries (bioMérieux, Marcy-l'Etoile, France), API ${ }^{\circledR}$ Coryne, API $^{\circledR} 20$ Strep, API ${ }^{\circledR} 20$ E, API ${ }^{\circledR} 20$ NE, API ${ }^{\circledR} 32$ STAPH, Rapid ID $32 \mathrm{~A}$ and $\mathrm{API}^{\circledR} 50 \mathrm{CH}$, were used.

A descriptive statistic was carried out using the statistical package SPSS 17.0 (IBM, Chicago, IL, USA).

\section{Results}

\subsection{Bacterial Growth in Sheep with Mandibular Osteomyelitis}

Bacterial growth was obtained in $194(94.63 \%)$ of the 205 OMO lesions sampled, in 64 samples (32.98\%) in pure growths, while in $130(67.01 \%)$, the results showed mixed cultures with two or more microorganisms isolated. In total, 482 different isolates were obtained. Table 1 shows the isolated microorganisms ordered by their frequency of isolation in relation to the total number of isolates (482) and the percentage of pure cultures obtained (Table 1).

Microorganisms of the genus Streptococcus were the most frequently isolated in OMO lesions in the present study (101/482: 20.95\%), of which 17 were in pure culture $(17 / 101$ : $16.83 \%$ ). In addition, in $47.42 \%$ of the analysed samples, some bacterium of the genus Streptococcus was isolated. Bacteria of genus Pseudomonas were the second most frequently encountered (41/482: 8.50\%), of which 9 were in pure culture (9/41: $21.95 \%)$. Trueperella pyogenes (35/482: 7.26\%) as well as microorganisms of genus Staphylococcus (32/482: 6.63\%) and Escherichia coli (30/482: 6.22\%), were also frequently found in OMO lesions, and in the case of T. pyogenes and E. coli in a high percentage obtained in pure culture $(9.37 \%$ and $10.93 \%$, respectively). 
Table 1. Isolated microorganisms ordered by their relevance within the number of isolates (482) and the percentage of pure cultures.

\begin{tabular}{|c|c|c|c|c|}
\hline Microorganisms & Pure & Pure Cultures (\%) & Total & Within Isolates (\%) \\
\hline$G^{o}$ Streptococcus & 17 & $26.56 \%$ & 101 & $20.95 \%$ \\
\hline Streptococcus suis & 0 & $0.00 \%$ & 5 & $1.04 \%$ \\
\hline Streptococcus bovis & 0 & $0.00 \%$ & 4 & $0.83 \%$ \\
\hline$G^{o}$ Pseudomonas & 9 & $14.06 \%$ & 41 & $8.50 \%$ \\
\hline Pseudomonas fluorenscens & 0 & $0.00 \%$ & 3 & $0.62 \%$ \\
\hline Pseudomonas alcaligenes & 0 & $0.00 \%$ & 2 & $0.41 \%$ \\
\hline Pseudomonas luteola & 0 & $0.00 \%$ & 1 & $0.21 \%$ \\
\hline Pseudomonas putida & 0 & $0.00 \%$ & 1 & $0.21 \%$ \\
\hline Trueperella pyogenes & 6 & $9.37 \%$ & 35 & $7.26 \%$ \\
\hline$G^{o}$ Staphylococcus & 2 & $3.13 \%$ & 32 & $6.63 \%$ \\
\hline Staphylococcus aureus & 1 & $1.56 \%$ & 6 & $1.24 \%$ \\
\hline Escherichia coli & 7 & $10.93 \%$ & 30 & $6.22 \%$ \\
\hline Fusobacterium necrophorum & 0 & $0.00 \%$ & 27 & $5.60 \%$ \\
\hline$G^{o}$ Bacillus & 3 & $4.68 \%$ & 27 & $5.60 \%$ \\
\hline$G^{o}$ Moraxella & 1 & $1.56 \%$ & 22 & $4.56 \%$ \\
\hline$G^{o}$ Micrococcus & 1 & $1.56 \%$ & 21 & $4.36 \%$ \\
\hline$G^{o}$ Enterobacter & 6 & $9.37 \%$ & 16 & $3.32 \%$ \\
\hline$G^{o}$ Klebsiella & 6 & $9.37 \%$ & 14 & $2.90 \%$ \\
\hline Mannheimia haemolytica & 4 & $6.25 \%$ & 14 & $2.90 \%$ \\
\hline Bacteroides fragilis & 0 & $0.00 \%$ & 13 & $2.70 \%$ \\
\hline$G^{o}$ Neisseria & 0 & $0.00 \%$ & 13 & $2.70 \%$ \\
\hline$G^{o}$ Acinetobacter & 0 & $0.00 \%$ & 12 & $2.49 \%$ \\
\hline$G^{o}$ Actinomyces & 0 & $0.00 \%$ & 8 & $1.66 \%$ \\
\hline$G^{o}$ Corynebacterium & 1 & $1.56 \%$ & 9 & $1.86 \%$ \\
\hline Corynebacterium urealyticum & 0 & $0.00 \%$ & 1 & $0.21 \%$ \\
\hline$G^{o}$ Prevotella & 0 & $0.00 \%$ & 8 & $1.66 \%$ \\
\hline$G^{o}$ Proteus & 1 & $1.56 \%$ & 7 & $1.45 \%$ \\
\hline Bacteroides capillosus & 0 & $0.00 \%$ & 5 & $1.04 \%$ \\
\hline Alcaligenes faecalis & 0 & $0.00 \%$ & 3 & $0.62 \%$ \\
\hline Salmonella enterica sub diarizonae & 0 & $0.00 \%$ & 3 & $0.62 \%$ \\
\hline Aerococcus urinae & 0 & $0.00 \%$ & 2 & $0.41 \%$ \\
\hline Aerococcus viridans & 0 & $0.00 \%$ & 2 & $0.41 \%$ \\
\hline Bacteroides urealyticus & 0 & $0.00 \%$ & 2 & $0.41 \%$ \\
\hline Bibersteinia trehalosi & 0 & $0.00 \%$ & 2 & $0.41 \%$ \\
\hline Cellulosimicrobium cellulans & 0 & $0.00 \%$ & 2 & $0.41 \%$ \\
\hline Fusobacterium nucleatum & 0 & $0.00 \%$ & 2 & $0.41 \%$ \\
\hline Pasteurella multocida & 0 & $0.00 \%$ & 2 & $0.41 \%$ \\
\hline$G^{o}$ Aeromonas & 0 & $0.00 \%$ & 1 & $0.21 \%$ \\
\hline$G^{o}$ Dermabacter & 0 & $0.00 \%$ & 1 & $0.21 \%$ \\
\hline$G^{o}$ Porphyromonas & 0 & $0.00 \%$ & 1 & $0.21 \%$ \\
\hline$G^{o}$ Rhodococcus & 0 & $0.00 \%$ & 1 & $0.21 \%$ \\
\hline$G^{o}$ Serratia & 0 & $0.00 \%$ & 1 & $0.21 \%$ \\
\hline Prevotella dentícola & 0 & $0.00 \%$ & 1 & $0.21 \%$ \\
\hline Yeast & 0 & $0.00 \%$ & 1 & $0.21 \%$ \\
\hline Total & 64 & & 482 & \\
\hline
\end{tabular}

\subsection{Bacterial Growth in Healthy Sheep}

Bacterial growth was obtained in the twelve samples collected from the gingival margins of periodontally healthy sheep analysed. All the cultures obtained were mixed, except in two animals, isolated Streptococcus bovis in pure culture (2/12: 16.66\%). In total, 91 different isolates were obtained from healthy mouths. Table 2 shows the isolated microorganisms and their relative importance in relation to the total number of isolates (91). 
Table 2. Isolated microorganisms in oral samples of healthy sheep ordered by the total number of isolations (91) is shown. The total isolates of each microorganism and the isolation in pure culture is reported.

\begin{tabular}{|c|c|c|c|}
\hline Microorganisms & Pure Isolates & Total Isolates & Within Isolates (\%) \\
\hline$G^{o}$ Streptococcus & & 15 & $16.48 \%$ \\
\hline Streptococcus bovis & 2 & 5 & $2.20 \%$ \\
\hline Streptococcus mitis & & 2 & $2.20 \%$ \\
\hline Streptococcus mutans & & 2 & $2.20 \%$ \\
\hline Streptococcus salivarius & & 1 & $1.10 \%$ \\
\hline Streptococcus suis & & 3 & $3.30 \%$ \\
\hline$G^{\circ}$ Staphylococcus & & 12 & $13.18 \%$ \\
\hline Staphylococcus lentus & & 2 & $2.20 \%$ \\
\hline Staphylococcus capitis & & 1 & $1.10 \%$ \\
\hline Staphylococcus cohnii & & 1 & $1.10 \%$ \\
\hline Staphylococcus xylosus & & 1 & $1.10 \%$ \\
\hline Staphylococus aureus & & 1 & $1.10 \%$ \\
\hline$G^{o}$ Pseudomonas & & 9 & $9.89 \%$ \\
\hline Pseudomonas aeruginosa & & 1 & $1.10 \%$ \\
\hline Pseudomonas vesicularis & & 1 & $1.10 \%$ \\
\hline Pseudomonas fluorescens & & 2 & $2.20 \%$ \\
\hline Pseudomonas putida & & 4 & $4.40 \%$ \\
\hline$G^{o}$ Moraxella & & 6 & $6.59 \%$ \\
\hline$G^{\circ}$ Aerococcus & & 5 & $5.49 \%$ \\
\hline Aerococus viridans & & 2 & $2.20 \%$ \\
\hline Ralstonia picketti & & 5 & $5.49 \%$ \\
\hline$G^{o}$ Corynebacterium & & 6 & $6.59 \%$ \\
\hline Corynebacterium afermentans & & 1 & $1.10 \%$ \\
\hline Corynebacterium yeikeim & & 1 & $1.10 \%$ \\
\hline Mannhemia haemolytica & & 4 & $4.40 \%$ \\
\hline Escherichia coli & & 2 & $2.20 \%$ \\
\hline$G^{o}$ Acinetobacter & & 2 & $2.20 \%$ \\
\hline$G^{o}$ Aeromonas & & 2 & $2.20 \%$ \\
\hline$G^{o}$ Brevibacterium & & 2 & $2.20 \%$ \\
\hline$G^{o}$ Micrococcus & & 2 & $2.20 \%$ \\
\hline$G^{o}$ Pantoea & & 2 & $2.20 \%$ \\
\hline$G^{o}$ Pasteurella & & 2 & $2.20 \%$ \\
\hline$G^{o}$ Klebsiella & & 2 & $2.20 \%$ \\
\hline Klebsiella oxitoca & & 1 & $1.10 \%$ \\
\hline Arcanobacterium haemolyticum & & 1 & $1.10 \%$ \\
\hline Bibersteinia trehalosi & & 1 & $1.10 \%$ \\
\hline Enterococcus avium & & 1 & $1.10 \%$ \\
\hline Escherichia adecarboxylata & & 1 & $1.10 \%$ \\
\hline Escherichia vulneris & & 1 & $1.10 \%$ \\
\hline$G^{o}$ Bacteroides & & 1 & $1.10 \%$ \\
\hline$G^{o}$ Enterobacter & & 1 & $1.10 \%$ \\
\hline$G^{o}$ Microbacterium & & 1 & $1.10 \%$ \\
\hline$G^{o}$ Propionibacterium & & 1 & $1.10 \%$ \\
\hline$G^{o}$ Serratia & & 1 & $1.10 \%$ \\
\hline Leifsonia aquatica & & 1 & $1.10 \%$ \\
\hline Rothia mucilaginosa & & 1 & $1.10 \%$ \\
\hline Yeast $^{\circ}$ & & 1 & $1.10 \%$ \\
\hline Total & 2 & 91 & \\
\hline
\end{tabular}

Microorganisms of genus Streptococcus were the most frequently isolated (15/91: $16.48 \%$ ), followed by bacteria of genus Staphylococcus (12/91: 13.18\%), Pseudomonas (9/91: $9.89 \%)$ and Moraxella (6/91: 6.59\%). 


\subsection{Comparison of Isolates from OMO Lesion and Oral Microbiota of Healthy Sheep}

Table 3 shows the comparison of the isolates percentages of the main microorganisms found in sheep with OMO and periodontally healthy sheep. As can be seen, microorganisms of the genus Streptococcus, Pseudomonas and Staphylococcus were the most frequently isolated in both studies. However, it is interesting to highlight the high presence of Trueperella pyogenes in the samples taken from OMO lesions, not having been isolated in any case from healthy sheep.

Table 3. Comparison between the main microorganisms isolated in sheep with mandibular osteomyelitis and periodontally healthy ewes.

\begin{tabular}{ccc}
\hline Microorganisms & $\begin{array}{c}\text { Within 482 Isolates (\%) } \\
\text { OMO Lesions }\end{array}$ & $\begin{array}{c}\text { Within 91 Isolates (\%) } \\
\text { Healthy Ewes }\end{array}$ \\
\hline$G^{\circ}$ Streptococcus & $20.95 \%$ & $16.48 \%$ \\
Streptococcus suis & $1.04 \%$ & $3.30 \%$ \\
Streptococcus bovis & $0.83 \%$ & $2.20 \%$ \\
$G^{\circ}$ Pseudomonas & $8.50 \%$ & $9.89 \%$ \\
Pseudomonas fluorenscens & $0.62 \%$ & $2.20 \%$ \\
Pseudomonas putida & $0.21 \%$ & $4.40 \%$ \\
Trueperella pyogenes & $7.26 \%$ & $0.00 \%$ \\
G Staphylococcus & $6.63 \%$ & $13.18 \%$ \\
Staphylococcus aureus & $1.24 \%$ & $1.10 \%$ \\
Escherichia coli & $6.22 \%$ & $2.20 \%$ \\
G Moraxella & $4.56 \%$ & $6.59 \%$ \\
\hline
\end{tabular}

\section{Discussion}

Ovine mandibular osteomyelitis is a widespread painful disease able to cause severe economic losses in affected farms. However, it has not been studied in-depth, particularly the microorganisms involved in the pathogenesis of this disorder. Likewise, to the authors' knowledge, the oral ecology and microbiology of the healthy sheep largely remain uncharacterised.

In the present study, the microorganisms isolated in affected and unaffected sheep were analysed. Microorganisms of the genus Streptococcus were the most frequently isolated, both in animals with OMO lesions (20.95\%) and healthy sheep (16.48\%), followed equally in both cases by microorganisms of the genus Pseudomonas and Staphylococcus. From extensive research of other species, it seems clear that an understanding of the microbial ecology of the mouth is fundamental to elucidating the aetiology of most oral diseases. The similarity of the microorganisms found in OMO lesions and healthy mouth in sheep could corroborate the idea that the microorganisms present in the normal oral microbiota end up causing mandibular osteomyelitis when an injury in the oral mucosa facilitates access, as it was proposed in previous studies [2,6]. Nevertheless, Riggio et al., in an experiment carried out comparing three healthy ewes with three with periodontitis, found different bacteria, being the most prevalent species in healthy ewes Enterobacter hormaechei and Hafnia alvei, and in animals affected with periodontitis, Mannheimia ruminalis and Moraxella caprae [12].

In addition, in our study, a wide variety of microorganisms were isolated from lesions of affected sheep, offering a clear idea that this disorder is not normally associated with a specific microorganism, but rather depends on environmental factors that cause lesions of the gingiva, that enables the entry of pathogens to the oral mucosa that eventually settle locally in bony tissues, causing mandibular osteomyelitis $[15,16]$. In a previous study carried out by our research team on 36,000 sheep, it was concluded that farm management factors, especially hard diets containing plant material with edges and sharp areas, plus acidic foods, including silage, had an evident influence on the presence of oral disorders in sheep. It was found that $98.33 \%$ of the 60 analysed farms had animals with jaw lesions, with an individual prevalence of 5.5\% [6]. In accordance with this, there are many and very varied microorganisms that have been associated with ovine periodontitis in the 
literature. Therefore, McCourtie et al. isolated Bacteroides and Fusobacterium organisms in $70 \%$ of the affected sheep [11], while Riggio et al. [12] found that the most prevalent microorganisms were Mannheimia ruminalis and Moraxella caprae and Borsanelli et al. [13] encountered that some of the species of the genera Porphyromonas and Prevotella correlate with ovine periodontitis. Similarly, Silva [17] identified Porphyromonas gingivalis, Tannerella forsythia, and Treponema denticola in a periodontitis outbreak in Brazil.

Similarly, a study on the occurrence of periodontitis and dental wear was performed in dairy goats, and the authors concluded that the main microorganisms isolated from sites with periodontitis were Fusobacterium nucleatum, Tannerella forsythia, and Fusobacterium necrophorum. However, although they found some similar microorganisms in periodontally healthy animals, as in the present study, the authors concluded that significant statistical association between the presence of identified periodontal pathogens and the occurrence of periodontitis was present [18].

However, some reports associate these disorders with a specific microorganism. That is the case of several outbreaks of acute mandibular osteomyelitis caused by Pseudomonas aeruginosa that were reported in Brazil, Iran, and Spain [8-10]. In the present study, Trueperella pyogenes and Escherichia coli were isolated in a high percentage in OMO lesions (7.26\% and $6.22 \%$, respectively) and rarely isolated in healthy animals $(0.00 \%$ and $2.20 \%$ ). In addition, both were frequently isolated in pure culture in affected animals $(9.37 \%$ and $10.93 \%$ ). The relevance of these microorganisms and others isolated in pure culture in OMO lesions should be more deeply studied.

\section{Conclusions}

Ovine mandibular osteomyelitis is a painful condition of sheep that has important welfare implications, reducing grazing efficiency, which contributes to malnutrition, weight loss, systemic health problems, poor quality of life and early culling from flocks. However, the aetiology of this disorder has not been yet deeply studied. Based on these and previous results, it seems that the normal microbiota of the oral cavity could be involved in the development of OMO lesions when there is an injury of the gingiva that enables the entry of bacteria to the oral mucosa that eventually settle locally in bony tissues, causing mandibular osteomyelitis. However, the implication of other microorganisms as primary pathogens in the development of mandibular osteomyelitis in sheep should be more deeply investigated.

Author Contributions: Conceptualization, D.L. and J.J.R.; Formal analysis, J.M.G.; Funding acquisition, L.M.F.; Investigation, M.R.d.A., D.L., J.P.B., L.M.F., S.V.-S. and J.J.R.; Methodology, D.L. and L.M.F.; Resources, J.J.R.; Software, M.R.d.A., J.M.G.; Validation, J.J.R.; Writing—original draft, D.L.; Writing-review and editing, M.R.d.A., J.P.B., L.M.F., J.M.G. and J.J.R. All authors have read and agreed to the published version of the manuscript.

Funding: This study was supported by the Aragón Government and the European Social Fund (Construyendo Aragón 2016-20).

Institutional Review Board Statement: All procedures were carried out under Project Licence PI 11/16 approved by the Ethics Committee for Animal Experiments from the University of Zaragoza. The care and use of animals were performed accordingly with the Spanish Policy for Animal Protection RD53/2013, which meets the European Union Directive 2010/63 on the protection of animals used for experimental and other scientific purposes.

Data Availability Statement: The data that support the findings of this study are available from the corresponding author request.

Acknowledgments: Authors would like to acknowledge veterinary colleagues and sheep farmers who have collaborated in the development of this work.

Conflicts of Interest: The authors declare no conflict of interest. 


\section{References}

1. Ridler, A.L.; West, D.M. Examination of teeth in sheep health management. Small Rumin. Res. 2010, 92, 92-95. [CrossRef]

2. Ruiz de Arcaute, M.; Ferrer, L.M.; Lacasta, D.; González, J.M.; De las Heras, M.; Borobia, M.; Ramos, J.J. Prevalence of dental and mandibular disorders in culled sheep in Spain. Aust. Vet. J. 2020, 98, 438-441. [CrossRef] [PubMed]

3. West, D.M. Dental disease of sheep. N. Z. Vet. J. 2002, 50 (Suppl. 3), 102-104. [CrossRef] [PubMed]

4. Smith, B.P. Large Animal Internal Medicine, 5th ed.; Elsevier-Mosby: St. Louis, MO, USA, 2015.

5. McGavin, M.D.; Carlton, W.W.; Zachary, J.F. Inflammation of bone. In Thompson's Special Veterinary Pathology, 3rd ed.; Mosby: St. Louis, MO, USA, 2001; pp. 441-443.

6. $\quad$ Ruiz de Arcaute, M.; Lacasta, D.; González, J.M.; Ferrer, L.M.; Ortega, M.; Ruiz, H.; Ventura, J.A.; Ramos, J.J. Management of risk factors associated with chronic oral lesions in sheep. Animals 2020, 10, 1529. [CrossRef] [PubMed]

7. Hoefs, M.; Bunch, T.D. Lumpy jaw in wild sheep and its evolutionary implications. J. Wildl. Dis. 2001, 37, 39-48. [CrossRef] [PubMed]

8. Benito-Peña, A.; Peris, B.; Aduriz, G.; Martínez, J.; Corpa, J.M. Purulent nasomaxillary and mandibular osteomyelitis in sheep caused by Pseudomonas aeruginosa. Vet. Rec. 2010, 166, 115-116. [CrossRef] [PubMed]

9. Amorim, R.M.; Toma, H.S.; Vulcano, L.C.; Ribeiro, M.G.; Fernandes, S.; Borges, A.S.; Chiacchio, S.B.; Goncalves, R.C. Outbreak of mandibular abscess by Pseudomonas aeruginosa in sheep. Pesq. Vet. Bras. 2011, 31, 747-750. [CrossRef]

10. Rasooli, A.; Nouri, M.; Esmaeilzadeh, S.; Ghadiri, A.; Ghadiri, D.; Javheri Koupaei, M.; Moazeni, M. Occurrence of purulent mandibular and maxillary osteomyelitis associated with Pseudomonas aeruginosa in a sheep flock in south-west of Iran. Iran. J. Vet. Res. 2018, 19, 133-136. [PubMed]

11. McCourtie, J.; Poston, I.R.; Brown, R.; Whittaker, C.R.; Spence, J.A.; Aitchison, G.U. A longitudinal study of the cultivable subgingival anaerobic bacteria isolated from sheep during the development of broken mouth periodontitis. J. Med. Micribiol. 1990, 31, 275-283. [CrossRef] [PubMed]

12. Riggio, M.P.; Jonsson, N.; Bennett, D. Culture-independent identification of bacteria associated with ovine 'broken mouth' periodontitis. Vet. Microbiol. 2013, 166, 664-669. [CrossRef] [PubMed]

13. Borsanelli, A.C.; Gaetti-Jardim, E.; Schewitzer, C.M.; Viora, L.; Busin, V.; Riggio, M.P.; Dutra, I.S. Black-pigmented anaerobic bacteria associated with ovine periodontitis. Vet. Microbiol. 2017, 203, 271-274. [CrossRef] [PubMed]

14. Brenner, D.J.; Krieg, N.R.; Staley, J.T.; Garrity, G.M.; Bergey, D.H. Bergey's Manual of Systematic Bacteriology, 2nd ed.; Springer: New York, NY, USA, 2005.

15. Orr, M.B. Study shows teeth problems causing much early culling in Otago/Southland. Surveillance 2015, 10, 8-11.

16. Silva, N.; Silveira, J.; Lima, D.H.; Bomjardim, H.; Brito, M.; Borsanelli, A.C.; Dutra, I.; Barbosa, J. Epidemiological, clinical and pathological aspects of an outbreak of periodontitis in sheep. Pesq. Vet. Bras. 2016, 36, 1075-1080. [CrossRef]

17. Silva, N.S. Periodontite em Ovinos no Estado do Pará: Etiologia, Aspectos Epidemiológicos e Clínico-Patológicos. Tese de Doutorado em Ciência Animal, Universidade Federal do Pará, Belém, PA, USA, 2015; 104p.

18. Campello, P.L.; Borsanelli, A.C.; Agostinho, S.D.; Schweitzer, C.M.; Gaetti-Jardim, E., Jr.; Döbereinere, J.; Dutra, I.S. Occurrence of periodontitis and dental wear in dairy goats. Small Rum. Res. 2019, 175, 133-141. [CrossRef] 